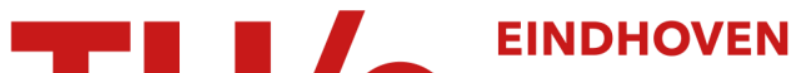

\section{Simulation of density segregation in vibrated beds}

Citation for published version (APA):

Zeilstra, C., Hoef, van der, M. A., \& Kuipers, J. A. M. (2008). Simulation of density segregation in vibrated beds. Physical Review E - Statistical, Nonlinear, and Soft Matter Physics, 77(3), 031309-1-13. [031309].

https://doi.org/10.1103/PhysRevE.77.031309

DOI:

10.1103/PhysRevE.77.031309

Document status and date:

Published: 01/01/2008

\section{Document Version:}

Publisher's PDF, also known as Version of Record (includes final page, issue and volume numbers)

\section{Please check the document version of this publication:}

- A submitted manuscript is the version of the article upon submission and before peer-review. There can be important differences between the submitted version and the official published version of record. People interested in the research are advised to contact the author for the final version of the publication, or visit the $\mathrm{DOI}$ to the publisher's website.

- The final author version and the galley proof are versions of the publication after peer review.

- The final published version features the final layout of the paper including the volume, issue and page numbers.

Link to publication

\section{General rights}

Copyright and moral rights for the publications made accessible in the public portal are retained by the authors and/or other copyright owners and it is a condition of accessing publications that users recognise and abide by the legal requirements associated with these rights.

- Users may download and print one copy of any publication from the public portal for the purpose of private study or research.

- You may not further distribute the material or use it for any profit-making activity or commercial gain

- You may freely distribute the URL identifying the publication in the public portal.

If the publication is distributed under the terms of Article $25 \mathrm{fa}$ of the Dutch Copyright Act, indicated by the "Taverne" license above, please follow below link for the End User Agreement:

www.tue.nl/taverne

Take down policy

If you believe that this document breaches copyright please contact us at:

openaccess@tue.nl

providing details and we will investigate your claim. 


\title{
Simulation of density segregation in vibrated beds
}

\author{
C. Zeilstra, M. A. van der Hoef, and J. A. M. Kuipers \\ Faculty of Science \& Technology, University of Twente, P.O. Box 217, 7500 AE Enschede, The Netherlands
}

(Received 6 June 2007; published 20 March 2008)

\begin{abstract}
We have investigated by numerical simulation the density segregation of fine equal-sized bronze and glass particles subject to vertical vibrations. The model was found to be capable of predicting the two main segregation forms ("bronze on top" and "sandwich") in roughly the same regions of the phase diagram as was found experimentally by Burtally et al. We investigated the effects of pressure air forcing, friction and restitution of kinetic energy in collisions, and box size on the segregation behavior. We find that next to the interstitial air friction also has a large influence on the formation of the sandwich structure.
\end{abstract}

DOI: 10.1103/PhysRevE.77.031309

PACS number(s): 45.70.Mg, 02.70.Ns, 02.70.Bf

\section{INTRODUCTION}

Granular matter is one of the most manipulated and complex types of material in the world. It can behave like a solid, a liquid, or a gas, depending on the processing conditions. One way to agitate granular material is by vibrations and, doing so, a wide range of interesting phenomena may occur, such as granular flows or segregation. The challenges resulting from this have made it an important research topic not only in academia, but in industries as well [1]. Vibrations may be applied in equipment such as gas-vibrofluidized beds, in order to enhance the fluidization behavior of cohesive particles [2,3]. Also, they may be applied in feeding systems for granular materials (i.e., hoppers), vibrated sieves, or conveyor belts. However, when particles with different properties are processed, undesirable segregation effects may occur, for example during blending operations (e.g., the pharmaceutical and ceramics industries) or by unintentional vibrations during transportation.

Most studies of granular matter were concerned with relatively large particles $(>1 \mathrm{~mm})$, where the effects of interstitial air can be safely ignored. However, for smaller particles, the effects of ambient air cannot be neglected: it has been demonstrated in several experiments that air can have a pronounced influence on the system's behavior. One of the most famous examples is Faraday heaping, which has become the common name for the general observation that fine particles on a vibrating or resonating plate tend to gather in piles, lines, or heaps [4-6]. It is clear that the presence of air is responsible for these phenomena, since under vacuum conditions no heaping of any kind is observed, as already found by Faraday. Another demonstration of the influence of air was given by Möbius et al. [7-9], who found that the air pressure has a profound effect on the rising time of a large intruder, submerged in a bed of smaller particles, to the extent that the intruders might even sink: the reverse Brazil nut effect. However, one of the most remarkable demonstrations of the effect of air in granular systems was reported by Burtally et al. $[10,11]$, who found experimentally that a mixture of fine bronze and glass particles of equal size $(55 \mu \mathrm{m}$ radius) segregates under vertical vibrations; the light particles are found to sink to the bottom, but only when air is forced through the granular bed. The effect appears to be very robust, and was also found in numerical simulations with very few particles (3000) and a simplified description of the gas phase [12]. In a recent paper [13], we showed that two different mechanisms are responsible for the segregation phenomena. In this paper we will give a full report of our results, in which we also investigate the sensitivity of the segregation process to the different physical parameters of the model.

The paper is organized as follows. First, we will discuss the numerical model and the simulation conditions that we used for the bronze-glass system. Then we will summarize the simulation results for a particular reference system, that is, for a fixed set of parameters connected with the particle properties (coefficient of restitution and friction), gas-phase properties (pressure), and system dimensions (box size and number of particles). For this system we systematically scan the experimental phase diagram of Burtally et al. [11] and briefly discuss the two mechanisms behind the major forms of segregation. Next, we vary the parameters that were hitherto kept fixed, in order to see what their effect is on the segregation. In particular, we determine the effect of pressure and air forcing, the effect of friction and restitution of kinetic energy in collisions, and the effect of the box size on the segregation behavior. Finally, we will briefly summarize and draw conclusions.

\section{MODEL DESCRIPTION}

In this section, the key features of the granular dynamicscomputational fluid dynamics model are described. We will first discuss the dynamics of the particles phase. Second, we treat the gas phase description, including the interaction with the bottom plate. For more details, the reader is referred to [14].

\section{A. Solid phase}

For the dynamics of the solid phase, we use a traditional molecular dynamics type scheme. The trajectory of each individual particle $i$ (mass $m_{i}$, diameter $d_{i}$ ) is given by Newton's law:

$$
m_{i} \frac{d^{2} \mathbf{r}_{i}}{d t^{2}}=\mathbf{F}_{c, i}+\mathbf{F}_{g, i}+\mathbf{F}_{d, i}+\mathbf{F}_{\nabla p, i}
$$

which is solved numerically by a first-order scheme. In Eq. (1), $\mathbf{F}_{c, i}$ is the total contact force, which is the sum of the 
individual contact forces $\mathbf{F}_{i j}$ exerted by all particles $j$ in contact with particle $i . \mathbf{F}_{g, i}$ is the gravitation force $m_{i} \mathbf{g}$, while $\mathbf{F}_{d, i}$ and $\mathbf{F}_{\nabla p, i}$ are the gas drag force and the force due to pressure gradients in the gas phase, respectively, on which we will elaborate when describing the gas phase.

For the calculation of $\mathbf{F}_{c, i}$, a three-dimensional (3D) linear spring and dashpot type soft sphere collision model along the lines of Cundall and Strack [15] is used. In this model, the force $\mathbf{F}_{i j}$ between two particles $i$ and $j$ is given by

$$
\begin{gathered}
\mathbf{F}_{i j, n}=-k_{n} \delta_{n} \mathbf{n}_{i j}-\eta_{n} \mathbf{v}_{i j, n}, \\
\mathbf{F}_{i j, t}=-k_{t} \delta_{t}-\eta_{t} \mathbf{v}_{i j, t} \quad \text { if }\left|\mathbf{F}_{i j, t}\right| \leq \mu_{f}\left|\mathbf{F}_{i j, n}\right| .
\end{gathered}
$$

In Eq. (2), $k_{n}$ is the normal spring stiffness $(\mathrm{N} / \mathrm{m}), \delta_{n}$ the overlap between the particles $(\mathrm{m}), \mathbf{n}_{i j}$ the normal unit vector, $\eta_{n}$ the damping coefficient $(\mathrm{N} \mathrm{s} / \mathrm{m}), \mathbf{v}_{i j, n}$ the velocity difference $(\mathrm{m} / \mathrm{s})$, and $\mu_{f}$ the dimensionless Coulomb friction coefficient. The quantities with subscript $t$ denote the tangential variables. As can be seen in Eq. (3), the tangential velocity of the particles reverses due to the spring if the tangential force is small. If the tangential force is larger, then frictional sliding occurs. The coefficients of normal and tangential restitution ( $e$ and $\beta_{0}$ ), which determine the amount of kinetic and rotational energy that is dissipated in a collision, enter the model via the normal and tangential damping coefficients $\left(\eta_{n}\right.$ and $\eta_{t}$ ). Note that, in principle, the normal spring stiffness $\left(k_{n}\right)$ in the soft sphere collision model is related to a physical property of the particle material, namely, the Young modulus. For computational reasons however, the spring stiffness is set to a much lower value, so that the time step used for the integration of the equations of motion of the particles can be kept relatively large; the drawback is that the overlap between the spheres is larger than the deformation that occurs during a collision in the real situation. We tested the effect for a bronze-on-top as well as a sandwich system using a normal spring stiffness of 20,200 , and $2000 \mathrm{~N} / \mathrm{m}$, which is still far below the stiffness that would follow from the Young modulus of glass. Although the formation time of the sandwich can differ when another stiffness is used, it did not affect the final results of the calculations. Therefore, in this work, a spring stiffness in the normal direction of $20 \mathrm{~N} / \mathrm{m}$ was used. The corresponding value of the tangential spring was $6.425 \mathrm{~N} / \mathrm{m}$ for the reference collision parameters. The time step for integrating the equations of motion of the particles was $2.08 \times 10^{-6} \mathrm{~s}$.

\section{B. Gas phase}

The dynamics of the gas phase are governed by the full Navier-Stokes equations, with a two-way coupling between the gas and the solid phase:

$$
\begin{gathered}
\frac{\partial\left(\varepsilon \rho_{g}\right)}{\partial t}+\nabla \cdot \varepsilon \rho_{g} \mathbf{u}=0, \\
\frac{\partial\left(\varepsilon \rho_{g} \mathbf{u}\right)}{\partial t}+\boldsymbol{\nabla} \cdot \varepsilon \rho_{g} \mathbf{u} u=-\varepsilon \boldsymbol{\nabla} p-\mathbf{S}-\boldsymbol{\nabla} \cdot \varepsilon \tau+\varepsilon \rho_{g} \mathbf{g},
\end{gathered}
$$

where $\varepsilon$ is the dimensionless volume fraction and $\rho_{g}$ is the density $\left(\mathrm{kg} / \mathrm{m}^{3}\right)$ of the gas phase, which is directly linked to the pressure $p$ via the equation of state of an ideal gas. For the viscous stress tensor $\tau\left(\mathrm{N} / \mathrm{m}^{2}\right)$, we use the general form for a Newtonian fluid [16]. The term $\mathbf{S}$ in Eq. (5) represents the effective momentum exchange with the solid phase, which can formally be written as

$$
\mathbf{S}=\frac{1}{V_{\text {cell }}} \int \sum_{i=1}^{N_{\text {part }}} \mathbf{F}_{d, i} \delta\left(\mathbf{r}-\mathbf{r}_{i}\right) d V,
$$

where the integral is over the volume of a computational cell, the summation is over all particles in the cell, and the drag force $\mathbf{F}_{d, i}$ is identical to what is used in the equation of motion for the solid phase. In our case, we have used the common Ergun and Wen and Yu drag force correlations [17]. In these correlations, the drag force is equal to

$$
\mathbf{F}_{d, i}=3 \pi \mu_{g} d_{i}\left(\mathbf{u}-\mathbf{v}_{i}\right) F(\operatorname{Re}, \varepsilon),
$$

with

$$
F(\operatorname{Re}, \varepsilon)= \begin{cases}\varepsilon^{-2.65}\left(1+0.15 \mathrm{Re}^{0.687}\right) & \text { for } \varepsilon>0.8, \\ \frac{150}{18} \frac{1-\varepsilon}{\varepsilon}+\frac{1.75}{18} \frac{\operatorname{Re}}{\varepsilon} & \text { for } \varepsilon<0.8,\end{cases}
$$

where $\mu_{g}$ is the dynamic gas viscosity ( $\mathrm{Pas}$ ) and $\mathbf{u}$ is the local flow velocity of the gas phase, while $\operatorname{Re}=d_{i} \rho_{g} \varepsilon \mid \mathbf{u}$ $-\mathbf{v}_{i} \mid / \mu_{g}$ is the particle Reynolds number. In the numerical implementation, the force-per-volume term $\mathbf{S}$ is distributed to the eight nearest grid points (nearest four when considering a 2D system) using a volume-weighing technique. For more details on the model, the reader is referred to Van der Hoef et al. [14].

The treatment of the bottom plate requires particular attention. There are different modeling options for incorporating these effects, but they can be traced back to two general forms, which differ with respect to the way in which the computational cells-which are used to evaluate the NavierStokes equations-are implemented. In the first approach the Navier-Stokes equations must be transformed so that the grid of computational cells remains fixed to the moving box and they are accelerating and decelerating with respect to the laboratory frame. In the second approach, the computational grid remains fixed to the laboratory framework and the vibrated box moves through the computational domain. Along the lines of this second approach, Tatemoto et al. [18] use a technique where all computational cells are fixed to the laboratory frame. The vibration is included by changing the size of the lowest row of computational cells according to the position of the bottom plate.

In this work, we follow the second approach, that is, we keep the computational grid fixed to the laboratory frame. In contrast to Tatemoto et al., we do not change the size of the computational cells. This means that the lowest computational cells will in general be cut by the bottom plate, so that they are only partially located in the vibrated box. When the amplitude of the vibration is larger than the size of the cells, computational cells will even find themselves completely outside the vibrated box when the bottom plate is at its highest position, and hence should be taken out of the update 
procedure. We have adjusted the model to incorporate these cell changes. The time step used for updating the gas phase information was $2.5 \times 10^{-5} \mathrm{~s}$.

We used free-slip boundary conditions between the gas phase and the box walls. The box itself is a closed system, containing air at atmospheric pressure without gas leaving or entering the system. When so desired, the bottom and top walls could be made permeable for the gas phase, by applying prescribed-pressure boundary conditions, so that the effect of air forcing may be investigated. Using this method, the buildup of pressure at the top of bottom of the box cannot occur.

\section{SIMULATION RESULTS FOR THE REFERENCE SYSTEM}

The simulation conditions for the reference system are as follows. The coefficient of restitution, which determines the amount of kinetic energy that is dissipated in a collision, is set to the values of 0.97 for the normal direction and 0.33 for the tangential direction, which, for glass particles with a radius of $750 \mu \mathrm{m}$, were found to be the most realistic values in a previous simulation study [19]. It is not obvious a priori, however, that the same parameters apply to $55 \mu \mathrm{m}$ radius particles, or for bronze-bronze and glass-bronze interactions. Unfortunately, for such small particles these parameters are very difficult to measure. For this reason, we have tested the effect of varying the collision parameters, the results of which we will discuss later on. For particle-wall interactions we use the same parameters as for particle-particle interactions. The friction coefficient is set to 0.1 . The shear viscosity $\eta$, average pressure $P$, and density $\rho_{g}$ of the gas phase are set to match the properties of air at ambient conditions: $\eta$ $=1.8 \times 10^{-5} \mathrm{~kg} / \mathrm{ms}, P=1$ bar, and $\rho_{g}=1.2 \mathrm{~kg} / \mathrm{m}^{3}$. The bulk viscosity is set to zero.

We will first study the effect of varying the frequency and amplitude for one particular system- to which we refer as the reference system-where all parameters associated with the solid phase, the gas phase, and the system dimensions are held fixed. These parameters have been chosen such that they are as close as possible to the experimental conditions. With respect to the system size, we could not match the experimental conditions of Burtally et al.: the ground area of the experimental box was $40 \times 10 \mathrm{~mm}^{2}$ and the granular bed height approximately $20 \mathrm{~mm}$. In order to make the simulation feasible with respect to computation time and computer memory, we had to reduce our simulation system to 8.25 $\times 0.65 \mathrm{~mm}^{2}$ with a granular bed height of approximately 6.5 $\mathrm{mm}$. However, we found that the main segregation phenomena were not affected by modifying the system size. More details on the finite-size effects are given later on, in which we will also investigate the effect of the gas and particle properties on the segregation phenomena.

In our reference system we have an initial situation of 7500 bronze particles $\left(\rho_{s}=8900 \mathrm{~kg} / \mathrm{m}^{3}\right)$, randomly mixed with 22500 glass particles $\left(\rho_{s}=2525 \mathrm{~kg} / \mathrm{m}^{3}\right)$. Both particle species have a radius of $55 \mu \mathrm{m}$, where a Gaussian size distribution $(\sigma=7.5 \mu \mathrm{m})$ was applied, as for excessive ordering of the bed under less vigorous shaking conditions; in the

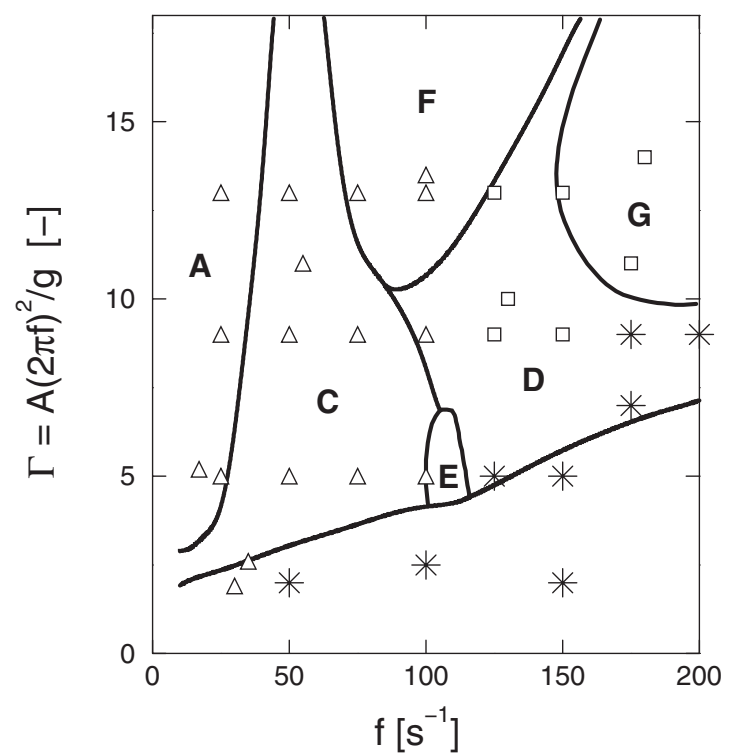

FIG. 1. Acceleration vs frequency, indicating the different types of segregation for the glass-bronze system, as taken from Burtally et al. [11]. The following segregation phenomena were observed in their experiments. Regions A and C, bronze on top; region D, sandwich formation; regions E, F, and G, fluctuations between sandwich and bronze-on-top configurations. The symbols mark the simulation results of this work for the reference system: triangles for bronzeon-top configurations, squares for sandwich configurations, asterisks for no segregation. In the simulations we did not find fluctuations between bronze-on-top and sandwich configurations.

experiments, the particles had a similar spreading in size $[10,11]$. Note that the box is of limited depth, so that the gas flow field is effectively two dimensional. We stress, however, that the particles can move in three dimensions. As mentioned by Burtally et al. [11], the separation is essentially a two-dimensional phenomenon, so that the limited depth of the system should not have a significant effect on the observations. We tested this by performing three-dimensional simulations for both bronze-on-top as well as sandwich conditions, using a system with equal width and depth (ground area $4.4 \times 4.4 \mathrm{~mm}^{2}$ ) and found similar results as for the twodimensional case.

We have studied different sets of vibration parameters corresponding to the various regions in the experimental phase diagram by Burtally et al. The results from our simulations are marked in the experimental phase diagram in Fig. 1.

We found that the model is able to successfully predict the main observations by Burtally et al., namely, the bronze-ontop configuration for low frequencies, and the sandwich formation for high frequencies. The transient behavior of the metastable regions E, F, and G could not be reproduced, however. As in the experiments, we found that no significant segregation occurred under vacuum conditions (see also Fig. 4), which we modeled by deactivating the coupling between the gas and particle phase. Also, for ambient pressure with porous top and bottom wall, we did not observe any segregation, which was also reported by Burtally et al. [11]. We will discuss this later on in more detail. It is interesting to 


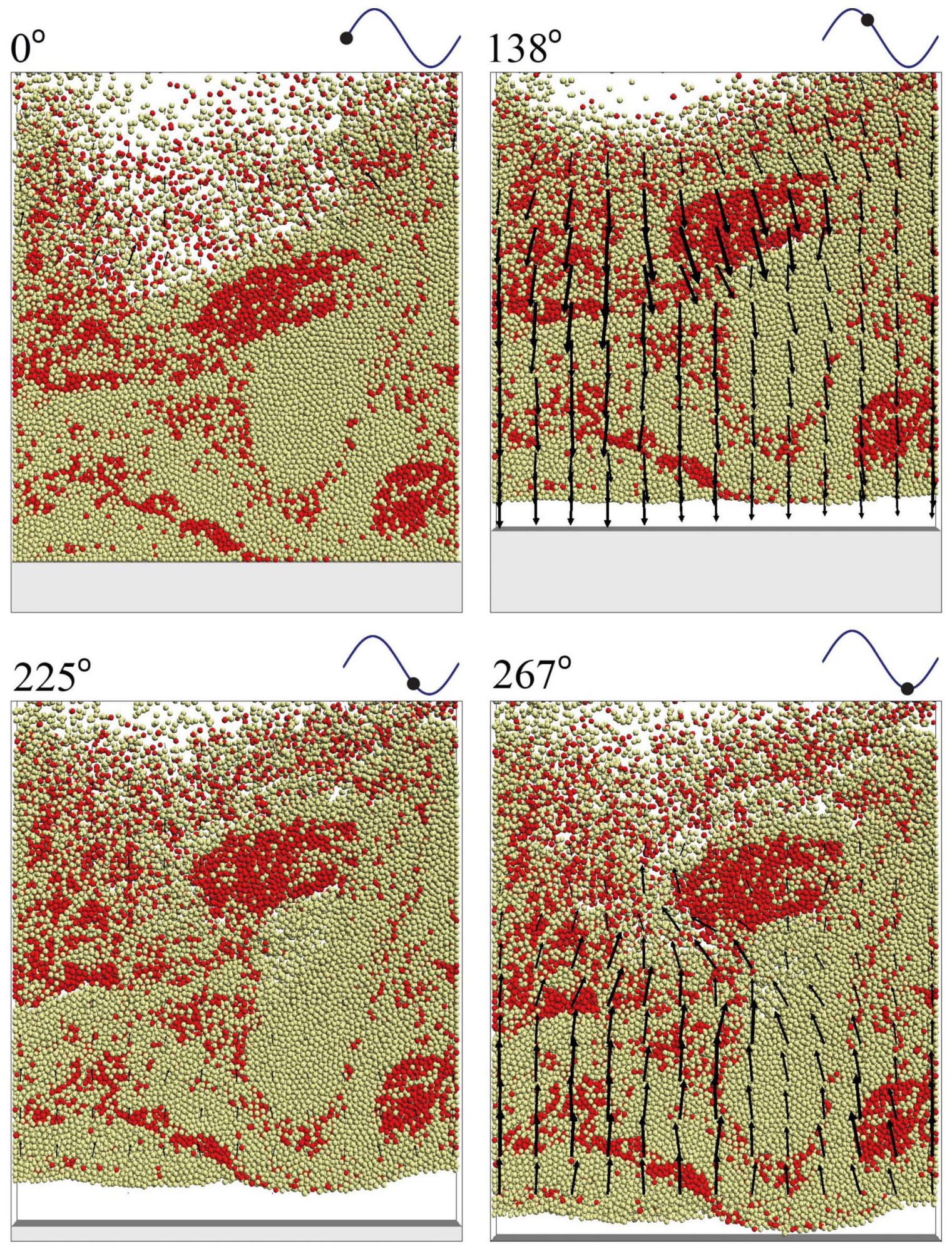

FIG. 2. (Color online) Simulation for bronze-on-top conditions, at four successive phases during one vibration cycle. The vectors indicate the air drag on the particles averaged per computational fluid dynamics cell (only one out of every two vectors is shown). The dark particles are bronze.

note that in a similar simulation study with 3000 particles by Milburn et al. [20], fluid-driven convection rolls were observed within the separate layers, which strengthened the separation mechanism. In our simulations we did not observe any significant fluid-driven convection, which was most likely caused by the absence of Faraday tilting at our conditions.

An explanation for the (counterintuitive) observation that the light glass particles sink to the bottom has been given in [13]. Briefly, the vertical vibrations set up a gas flow which 

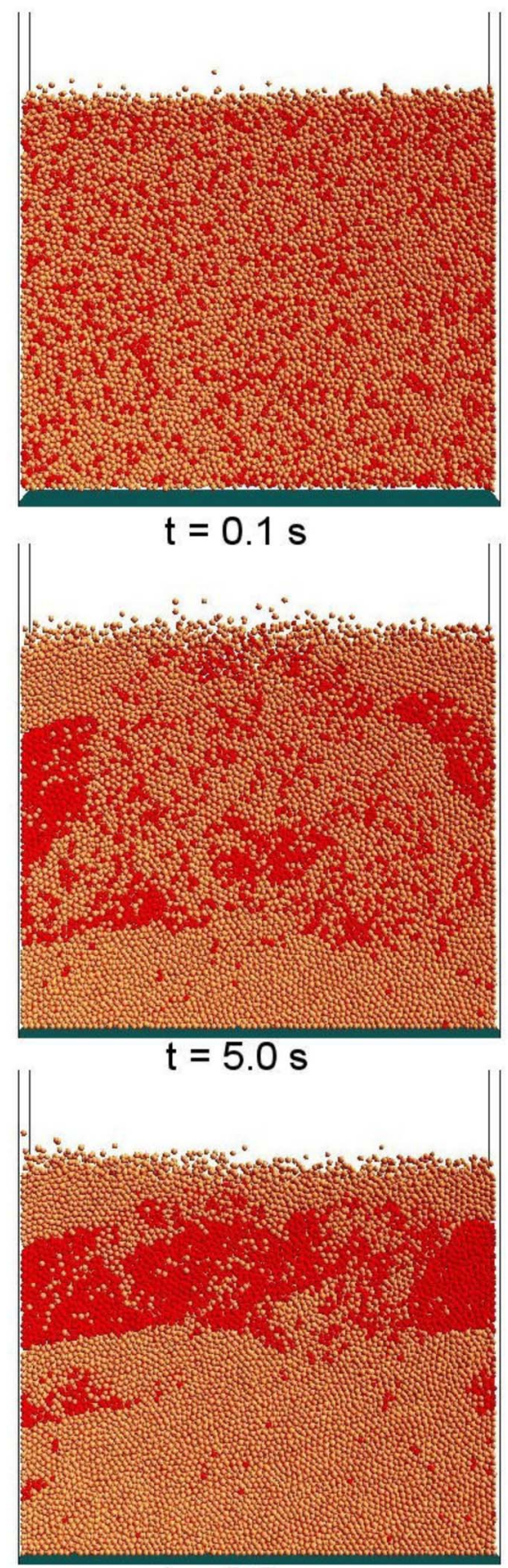

$t=9.0 s$

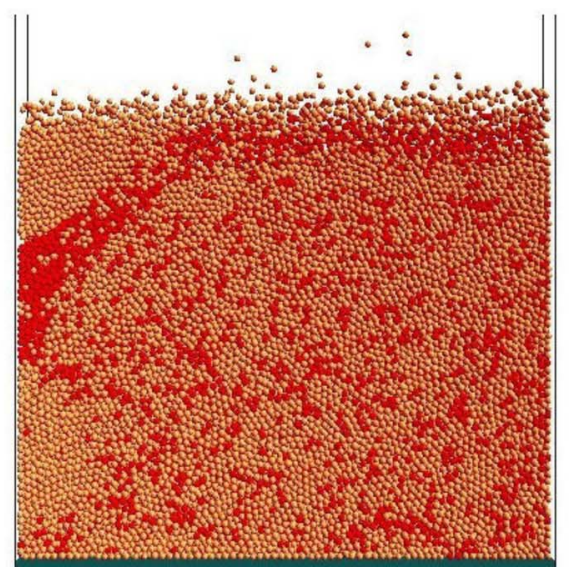

$\mathrm{t}=2.0 \mathrm{~s}$

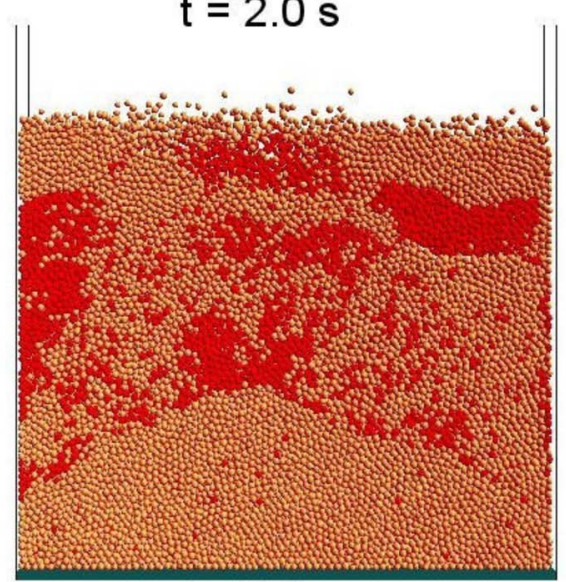

$\mathrm{t}=7.0 \mathrm{~s}$

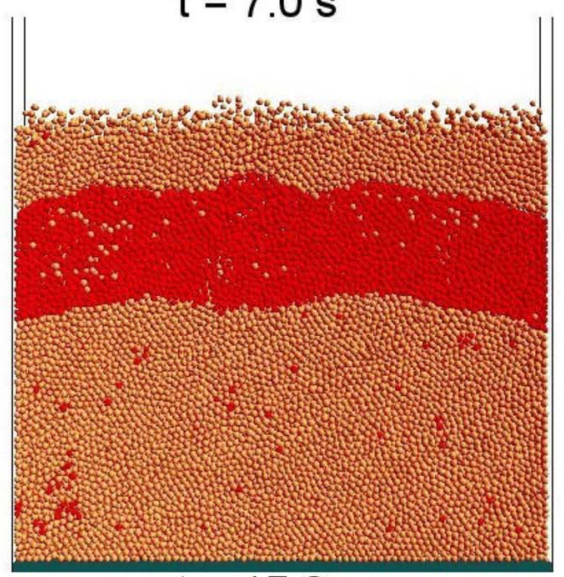

$\mathrm{t}=15.0 \mathrm{~s}$
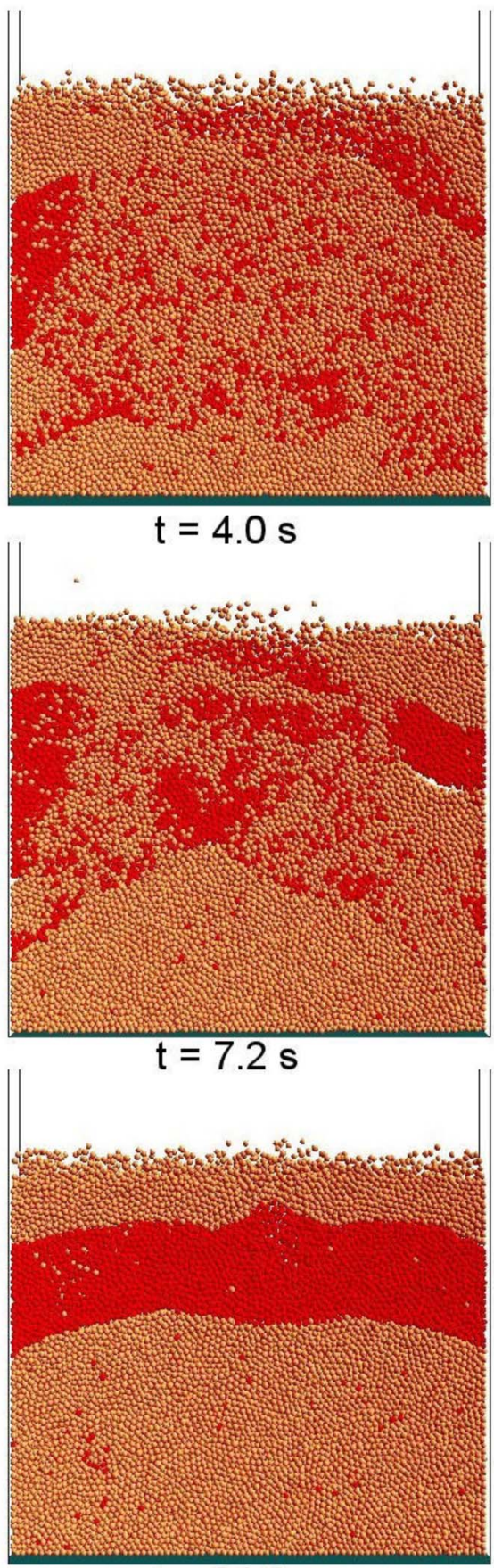

$\mathrm{t}=21.0 \mathrm{~s}$

FIG. 3. (Color online) Series of snapshots for the sandwich system $\left(A_{z}=0.147 \mathrm{~mm}, f_{z}=130 \mathrm{~Hz}, \Gamma=10\right)$. The dark particles are bronze. After the formation of the glass-bronze-glass sandwich, the configuration was stable for the time that we simulated (60 s).

is periodic with the vibration frequency; see Fig. 2. This, in combination with the cyclic compaction and decompaction of the granular bed, makes the bronze move to the top for the areas on the left-hand side in the phase diagram. The observation that compaction can lock particles against further movement has been reported previously for the Faraday heap [6] and for the Brazil nut effect [9,21]. Deactivation of gravity confirms these findings. When this is done for a segregated bronze-on-top system, the particles rapidly spread throughout the box. The bronze and glass mix, that is, we find small bronze and glass clusters randomly throughout the box. Compact regions do not occur and the locking effect is not present.

\section{SANDWICH SYSTEM}

We next focus on a sandwich system, which is obtained by setting the vibration parameters to $f_{z}=130 \mathrm{~Hz}$ and $A_{z}$ $=0.147 \mathrm{~mm}(\Gamma=10)$.

In Fig. 3 we show some snapshots of the simulation. Note that the time scale on which the layer is formed is much longer than for the bronze-on-top system, which already sug- 
gests that another mechanism will be responsible for the observed behavior. A similar analysis as for the bronze-on-top system was performed for the first $2 \mathrm{~s}$ of this simulation. The rate at which (some of) the bronze initially clusters at the top is a factor of 25 lower. This can be attributed to the smaller amplitude of vibration, so that the void between granular bed and bottom plate is much smaller for the sandwich than for the bronze-on-top system (1.5 vs 6.5 particle diameters). The time of flight of the granular layer will be smaller for the sandwich system, resulting in an increased packing fraction, varying between 0.56 and 0.59 (compared to $0.45-0.55$ for the bronze-on-top system). This will make it more difficult for the particles to move relative to each other. However, after some of the bronze has clustered on top, a completely different phenomenon is observed. When a bronze cluster at the top becomes sufficiently large, it becomes too heavy for the bed to support it, and it suddenly falls through the bed, setting up a large-scale convection roll. Within this motion, the glass-rich layer just below the bronze cluster is pushed to the bottom where it compactifies, so that the bronze cluster cannot reach the bottom, but ends up in the middle of the bed. This happens first at both sidewalls (see Fig. 3 at $t$ $=5.0 \mathrm{~s}$ ), but eventually all top bronze clusters sink through the bed, so that a bronze-rich middle layer is formed, leaving an almost pure glass layer at the top. At the same time, the weak bronze-to-top mechanism that is still in play causes the middle bronze-rich layer and the bottom glass-rich layer to exchange their impurities. The final result is an almost perfect separation of glass and bronze into a sandwich structure. Note that, for water-immersed systems, Leaper et al. [22] found that vertical vibration would always lead to bronze on top, even when initially sandwich structures are formed, suggesting that the sandwich structure might be a metastable state. In our simulation in air, we found that the sandwich layer was stable for the time that we simulated $(60 \mathrm{~s})$. Although sometimes convection rolls could be observed within the three separate layers, the apparent shear between the layers did not induce global mixing. Leaper $e t$ al. explained this with the observation that the granular convection occurs only while the gap is open, at least for water-immersed glassbronze systems.

The observations for both the bronze-on-top as well as the sandwich system suggest that different segregation mechanisms dominate for different vibration parameters. Convective motion-during which bronze moves downward—can be observed at low-amplitude and high-frequency vibrations, while relative movement due to the forcing of air is dominant at the higher-amplitude vibrations. To further look into this, we studied the vibration series at acceleration $\Gamma=9$. We varied the vibration frequency from 25 to $200 \mathrm{~Hz}$, with steps of $25 \mathrm{~Hz}$, keeping the acceleration at a constant value of 9 , so that the amplitude becomes smaller. We found that, when we move from the bronze-on-top to the sandwich region of the experimental phase diagram (i.e., we increase the vibration frequency), the convective mechanism becomes more important. At 25 and $50 \mathrm{~Hz}$, we find the regular relative movement type of segregation. The simulations at 75 and $100 \mathrm{~Hz}$ start to show characteristics of the sandwich system: large glass clusters moving downward near the walls. Only for 125 and $150 \mathrm{~Hz}$ does a sufficiently large amount of bronze follow in
TABLE I. Values of the different densities $\left(\mathrm{kg} / \mathrm{m}^{3}\right)$ in the artificial sandwich simulations. The subscripts $b$ and $g$ denote bronze and glass, respectively. $M_{b}$ is the heavy mass, $I_{b \text {,coll }}$ the inertia in collisions, and $I_{b, \text { gas }}$ the inertia due to the gas. $V_{p}$ is the volume of a particle.

\begin{tabular}{lcccc}
\hline \hline & Reference & (a) & (b) & (c) \\
\hline$M_{b} / V_{p}$ & 8900 & 4100 & 8900 & 4100 \\
$M_{g} / V_{p}$ & 2525 & 4100 & 2525 & 4100 \\
$I_{b, \text { coll }} / V_{p}$ & 8900 & 8900 & 4100 & 4100 \\
$I_{g, \text { coll }} / V_{p}$ & 2525 & 2525 & 4100 & 4100 \\
$I_{b, \text { gas }} / V_{p}$ & 8900 & 8900 & 8900 & 8900 \\
$I_{g, \text { gas }} / V_{p}$ & 2525 & 2525 & 2525 & 2525 \\
\hline \hline
\end{tabular}

the wake of the glass to form the sandwich. Note that, when the vibration frequency is increased, the formation of the sandwich requires an increasingly longer time, and for frequencies beyond $175 \mathrm{~Hz}(\Gamma=9)$, we did not observe significant segregation for the time that we simulated.

We further investigated the sinking behavior of the bronze clusters under sandwich conditions. The question that arises is which effect is responsible for this sinking behavior: (i) the difference in heavy mass, i.e., the different gravity force on the bronze and glass particles, or (ii) the difference in inertial mass in collisions, which will cause a bronze cluster to penetrate the glass layer when pounding on it in the second part of the vibration cycle. To answer this question we have performed purely artificial simulations, where we modified the differential masses. The different values for the masses are summarized in Table I. We first investigated case (a), where the particles have the same gravity. Here, we choose the standard particle densities of 8900 and $2525 \mathrm{~kg} / \mathrm{m}^{3}$ for the particle species, but rescaled the acceleration due to gravity with $4100 / 2525$ for glass and $4100 / 8900$ for bronze, so that the gravity force is the same for both species. Doing this, we still observed the sinking of the bronze clusters, although less pronounced than under "real" conditions, so that the final result is a mixed sandwich and bronze-on-top state. We chose a value of $4100 \mathrm{~kg} / \mathrm{m}^{3}$, in order to keep the total mass of the granular bed to the same value as under reference conditions. However, we also investigated scaling with 2500 instead of $4100 \mathrm{~kg} / \mathrm{m}^{3}$ and found similar results. We next investigated case (b): the effect of the particles having the same inertial mass in collisions. To this end, we used a density of $4100 \mathrm{~kg} / \mathrm{m}^{3}$ for both particle species. We then rescaled the gas and gravity accelerations of glass and bronze by $4100 / 2525$ and $4100 / 8900$, respectively. Thus, the differential effects of drag and gravity were restored, and the effects of differential mass in collisions removed. We found that the characteristic sinking of bronze clusters as precursor to sandwich formation did not occur. We finally investigated case (c), namely, the effect of having only a difference in gas forces. Here, again, we used a density of $4100 \mathrm{~kg} / \mathrm{m}^{3}$ for both particle species and rescaled only the gas accelerations of glass and bronze by 4100/2525 and 4100/8900, respectively. We now found that bronze goes to the top even for vibration conditions where normally sandwich structures are observed. 


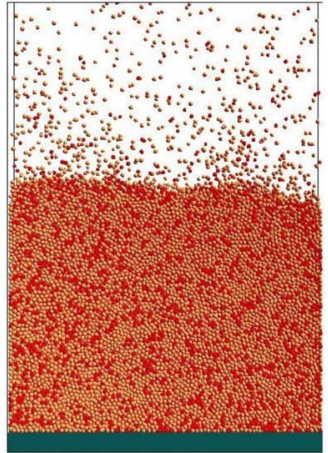

$\mathrm{t}=0.1 \mathrm{~s}$

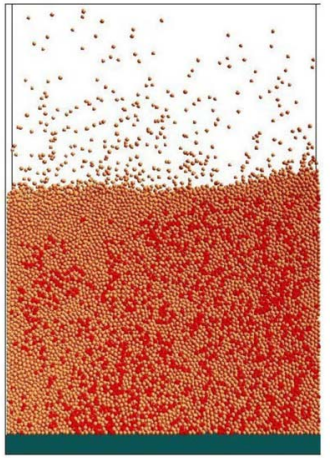

$\mathrm{t}=2.0 \mathrm{~s}$

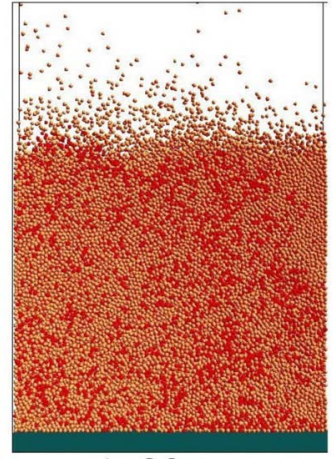

$\mathrm{t}=0.3 \mathrm{~s}$

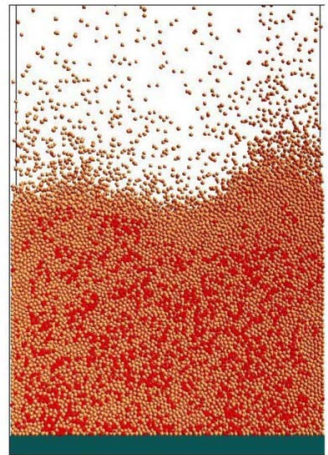

$\mathrm{t}=4.0 \mathrm{~s}$

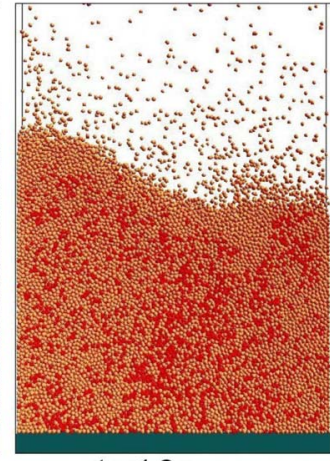

$\mathrm{t}=1.3 \mathrm{~s}$

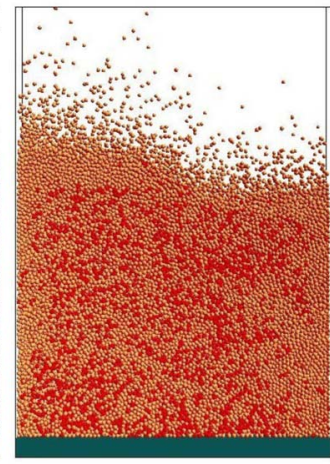

$t=6.9 s$
FIG. 4. (Color online) Series of snapshots for the bronze-on-top vibration parameters $\left(A_{z}\right.$ $\left.=0.9 \mathrm{~mm}, f_{z}=55 \mathrm{~Hz}, \Gamma=11\right)$ for vacuum conditions. The granular bed moves wildly and no significant clustering is observed.
From the observations in our artificial simulations, it becomes clear that under real conditions the different inertia in collisions causes the bronze clusters on top to sink through the bed, leading to the sandwich formation.

\section{VARYING THE GAS, PARTICLE, AND BOX PARAMETERS}

\section{A. Effects of pressure}

From the experiments of Burtally et al. $[10,11]$ and the simulations of Biswas et al. [12] and Zeilstra et al. [13], it is clear that the forcing of air through the system is responsible for the segregation phenomenon. Indeed, we found that, when we simulated the system at vacuum conditions, no segregation was found, irrespective of the shaking parameters. A series of snapshots for one particular system $\left(f_{z}=55 \mathrm{~Hz}, \Gamma\right.$ $=11$ ) is shown in Fig. 4 . The bed surface was unstable and surface waves traveled from sidewall to sidewall. The bronze particles showed only a tendency to form small clusters (typical size fewer then ten particles), but remained mixed with the glass particles.

Further evidence of the importance of air forcing was obtained by applying prescribed-pressure boundary conditions to the bottom and top walls of the box. Effectively, such a boundary condition prohibits pressure buildup, as is experimentally the case when a porous plate with negligible pressure drop is used. We found for both bronze-on-top and sandwich cases that, if either the bottom or the top wall was made porous, segregation would still occur. However, if both walls were made porous, no segregation occurred. We also carried out simulations with larger particles $(0.5,1.5$, and $2 \mathrm{~mm}$ diameter) under shaking conditions where for $110 \mu \mathrm{m}$ diam- eter particles a bronze-on-top configuration was found. Convection rolls developed in the granular bed and some slight coarsening could be observed. However, no major segregation occurred for these larger particles, confirming the importance of the gas for smaller-sized particles.

Since the presence of air has such a pronounced influence even at atmospheric pressure, it is interesting to see what happens when we increase the pressure further to $100 \mathrm{bar}$, again for both regimes $\mathrm{C}$ and D. Note that, even for $100 \mathrm{bar}$, the density of the gas phase is still small compared to the density of the particles (5\%), so that we can still neglect the "added mass" force associated with the displacement of the continuous phase.

For regime $\mathrm{C}$, we find that at 100 bar bronze clusters are formed almost immediately (within $0.1 \mathrm{~s}$ ) throughout the granular bed; see Fig. 5. The clusters coalesce and move to the top. The most important difference from the simulations at atmospheric pressure is that the tilting of the bed surface during the segregation is suppressed. When the bronze particles have reached the bed surface, some small bronze clusters remain in the glass phase, and also in the bronze phase a few glass particles remain. We recall that, at atmospheric conditions, glass can be found in the bronze phase and occasionally glass is even spilled over the bronze due to surface tilting; the 100 bar simulations, however, exhibit almost no tilting. Glass particles remaining in the bronze-rich layer eventually move downward to join the bulk glass layer underneath. The result is a much purer bronze phase as compared to the atmospheric case.

When the pressure for regime D (sandwich structure) is increased to 100 bar we observe slower clustering compared to the atmospheric case. While we find a sandwich in approximately $10 \mathrm{~s}$ for atmospheric pressure, for the $100 \mathrm{bar}$ 

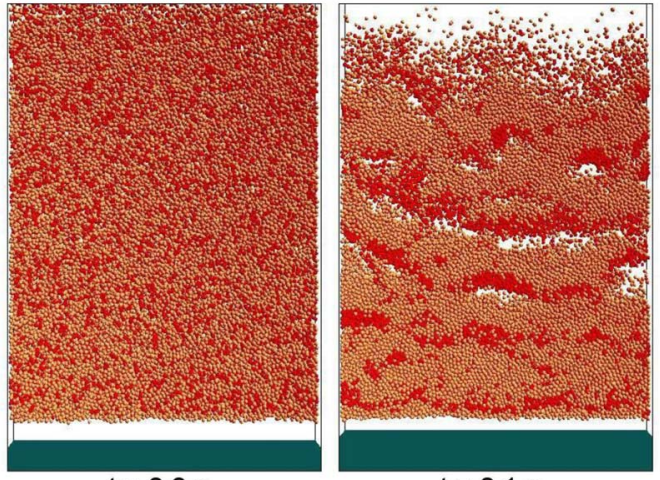

$\mathrm{t}=0.1 \mathrm{~s}$

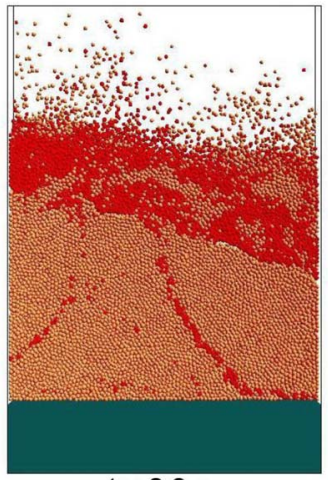

$t=0.8 s$

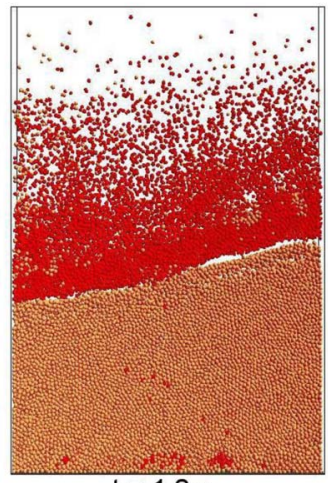

$\mathrm{t}=1.3 \mathrm{~s}$

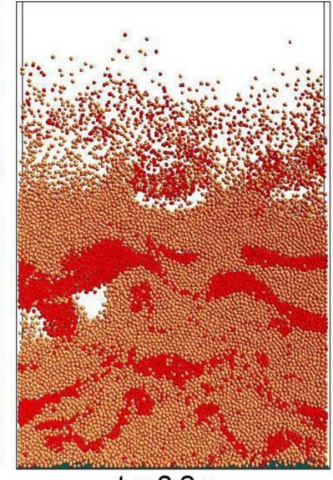

$t=0.3 s$

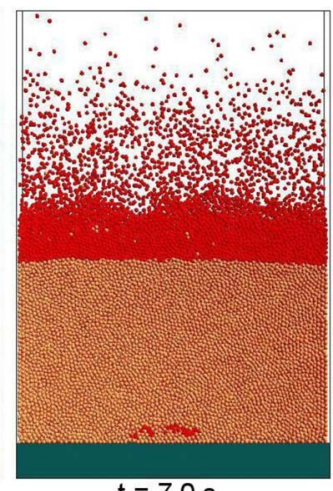

$t=7.0 s$
FIG. 5. (Color online) Series of snapshots leading to the bronze-on-top structure $\left(A_{z}\right.$ $\left.=0.9 \mathrm{~mm}, f_{z}=55 \mathrm{~Hz}, \Gamma=11\right)$ for 100 bar gas phase pressure. The bronze particles immediately form clusters, which move to the top of the granular bed. In contrast to the results at atmospheric pressure, the bronze layer contains only a few glass particles and almost no surface tilting is observed. simulation we observe a sandwich only after $30 \mathrm{~s}$. We find that the bronze clusters fall through the granular bed at a much slower rate compared to the atmospheric case. Apparently, the increased density (and thus drag force) at higher gas pressures hinders the sinking of bronze clusters; it may be that the bronze-on-top effect becomes more important. Leaper et al. [22], who did experiments for water-immersed systems, suggest that the sandwich itself may be a metastable state. Following this line, this may explain why the sandwich is more slowly formed in our high-pressure simulations.

\section{B. Effect of particle parameters}

We next study the effect of the particle-particle and particle-wall interaction parameters, in particular those that determine the magnitude of the energy dissipation in collisions, i.e., the normal restitution and friction coefficients. It is well known that dissipation drives the formation of clusters in monodisperse systems, first observed by Goldhirsch and Zanetti for a granular gas [23], and later also found in other granular systems such as fluidized beds [24] or vibrated beds with multiple compartments [25].

We first study the effect of the particle-particle friction coefficient $\mu_{p p}$ and the particle-wall friction coefficient $\mu_{p w}$ on the bronze-on-top and sandwich systems, while keeping the other interaction parameters and the gas phase properties the same as for the reference system. We start our analysis with the bronze-on-top case. For the reference system $\left(\mu_{p p}\right.$ $=\mu_{p w}=0.1$ ), the final bronze and glass layers are large and well defined. Tilting of the bed surface is regularly observed, which occasionally leads to glass from the lower layer spilling over the bronze layer on top. When we redo this simula- tion, but now with all friction deactivated, we find the segregation to be much less pronounced. Although bronze still moves to the top, the top layer is less compact and with a much higher glass content in the top bronze layer. The simulation with only wall friction activated shows similar behavior. By contrast, when we activate only the particle-particle friction (keeping the wall friction to zero), we find that the bronze layer contains only up to $10 \%$ of glass, and we observe nearly no surface tilting. It appears that the particleparticle friction is required for a good separation, while wall friction enhances tilting. In a similar manner, we tested the effect of increasing one or both of the friction components to the value of 0.4 , while the other value remained at the standard value of 0.1 . We found that the qualitative behavior in all three cases was similar to that of the reference system, that is, bronze clustering and moving to the top, after which tilting and subsequent glass spilling are observed. The amount of tilting could be reduced by deactivating the friction of the the two principal box faces.

We carried out similar tests for the sandwich system, the results of which are summarized in Table II. In the case that there is no particle-particle friction, we made the remarkable observation that bronze gathers at the bottom of the box; see Fig. 6. Starting from an initially mixed state, the bronze appears to percolate downward through the granular bed and a nearly pure glass layer is growing near the bed surface. The boundaries between bronze-rich and glass-rich sections are diffuse. We made this observation for all three values of $\mu_{p w}$. When we have only particle-particle friction activated, we still find the sandwich, although the formation time is longer. Next, as in the bronze-on-top system, we increased one or both of the friction components to the value of 0.4 , while the 
TABLE II. Final position (bottom, middle, or top) of the bronze layer for various combinations of the particle-particle $(p p)$ and particle-wall $(p w)$ friction coefficients. The frequency is set to $f_{z}$ $=130 \mathrm{~Hz}$; the dimensionless acceleration to $\Gamma=10$. In parentheses we show the time it roughly takes to form the sandwich structure, starting from a mixed state. The central box $\left(\mu_{p p}=\mu_{p w}=0.1\right)$ represents the reference system shown in Fig. 3. The case $\mu_{p p}=\mu_{p w}$ $=0.0$ is shown in Fig. 6 .

\begin{tabular}{lccc}
\hline \hline & \multicolumn{3}{c}{$\mu_{p w}$} \\
$\mu_{p p}$ & 0.0 & 0.1 & 0.4 \\
\hline 0.0 & Bottom & Bottom & Bottom \\
0.1 & Middle $(40 \mathrm{~s})$ & Middle $(10 \mathrm{~s})$ & Top \\
0.4 & Middle $(20 \mathrm{~s})$ & Middle $(10 \mathrm{~s})$ & Top \\
\hline \hline
\end{tabular}

other value remained equal to 0.1 . When we increase the wall friction to 0.4 , we find that the bronze moves to the top via large-scale convection currents, and not with the mechanism discussed in Sec. III. When both friction components are set to 0.4 , we also find that the bronze moves to the top. When $\mu_{p p}=0.4$ and $\mu_{p w}=0.1$, we find the sandwich structure. While in the reference system also some convective motion was observed, we suspect that the strong convective current that brings the bronze to the top for $\mu_{p w}=0.4$ is generated by the wall. As observed before in the $\mu_{p w}=0.0$ case, the wall friction does not seem to be strictly required for the system to move to a sandwich structure, which suggests that the gas forces and particle-particle friction are sufficient to obtain a sandwich structure. However, when the wall friction dominates $\left(\mu_{p w}=0.4\right)$, wall-generated convection will deposit the bronze on the top.

We further investigated the effect of wall friction by deactivating the friction between wall and particles only for the principal cell faces, leaving the friction with the two smaller sidewalls and the bottom plate intact. For the $f_{z}=55 \mathrm{~Hz}, \Gamma$ $=11$ case, we observe the regular formation process, namely, bronze moving to the top, where the main difference from the reference system was that the amount of interface tilting was strongly reduced. For $f_{z}=130 \mathrm{~Hz}, \Gamma=10$, we observed the same behavior as in the reference case (sandwich formation), although the sinking appeared to proceed more readily. For a deep (19.5 mm) granular bed (see the next section), we found that the final depth of the sandwich depended on the presence of friction on the principal cell faces.

We further investigated the role of the wall friction coefficient in $3 \mathrm{D}$ simulations, where the ground area was 4.4 $\times 4.4 \mathrm{~mm}^{2}$ and granular bed height $6.5 \mathrm{~mm}$ (105 600 particles). For the standard friction parameters, we found the sandwich structure, while deactivation of all friction shows bronze gathering at the bottom of the box, which we also found for the pseudo-2D systems. Having only interparticle friction, we again found the sandwich, but-as we also observed in the pseudo-2D systems - the formation time is longer.

We next consider the effect of the normal restitution coefficient. We first note that all the collision parameters used in the reference system were obtained via an experimental measurement technique as described by Kharaz et al. [26] for glass particles with a radius of $750 \mu \mathrm{m}$. Since the normal restitution coefficient depends-among other parameters - on the size of the particle, it is best to assume that the parameters used in this simulation are not extremely accurate. Additionally, we do not know the interaction parameters for bronze-glass and bronze-bronze collisions. However, we do expect that the normal restitution coefficient for bronze-bronze collisions is smaller than the one for glassglass interactions since bronze is more easily deformed than glass. Since the precise value of the restitution coefficient is not known, we can only test the sensitivity of the results with respect to these collision parameters. We did a simulation for the bronze-on-top system in which we used extremely low restitution coefficients, while keeping the other parameters to the reference values. For the glass-glass interactions we used a normal restitution coefficient of 0.6 , for the bronze-glass interactions a value of 0.4 , and for the bronze-bronze interactions a value of 0.2 .

Under atmospheric conditions at $f_{z}=55 \mathrm{~Hz}$ and $\Gamma=11$, we find that the bronze moves to the top as in the reference

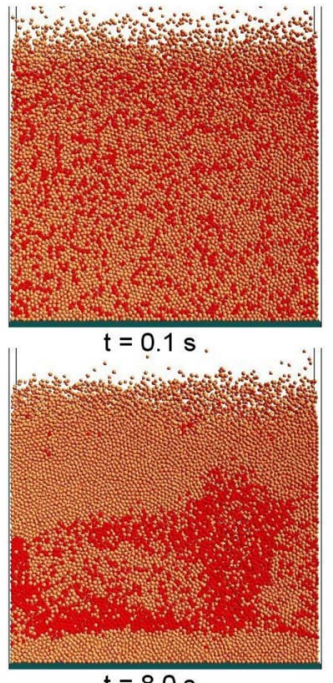

$\mathrm{t}=8.0 \mathrm{~s}$

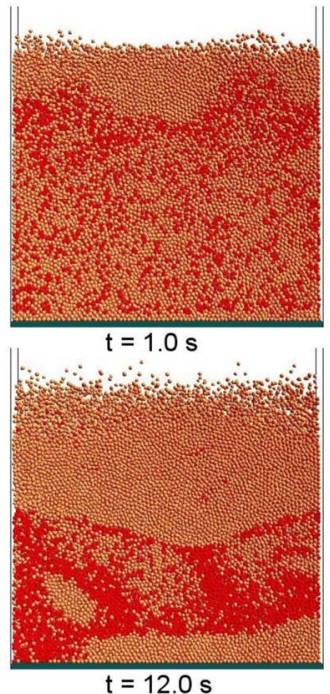

$t=12.0 s$

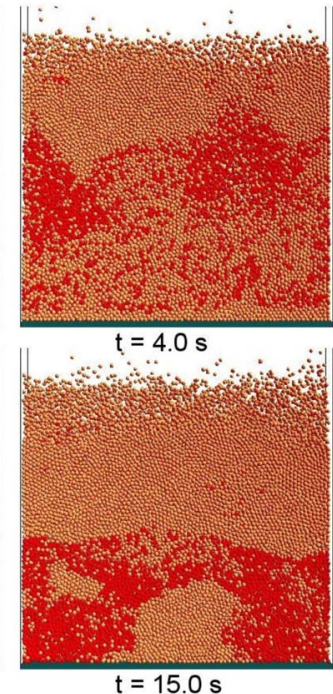

$t=15.0 s$
FIG. 6. (Color online) Series of snapshots for the sandwich system $\left(A_{z}=0.147 \mathrm{~mm}, f_{z}\right.$ $=130 \mathrm{~Hz}, \Gamma=10$ ), with all friction deactivated. The sandwich is not formed and the bronze gathers at the bottom of the box. 


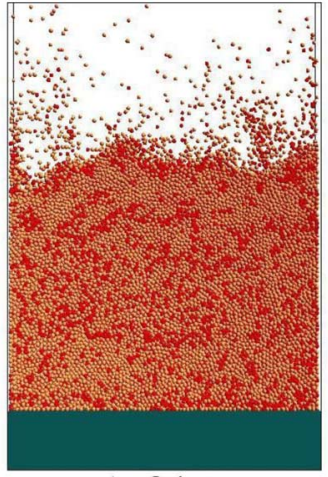

$t=0.1 s$

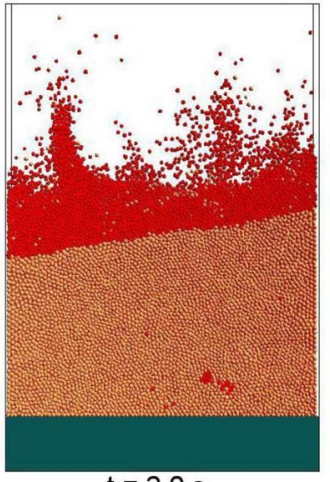

$t=2.0 s$

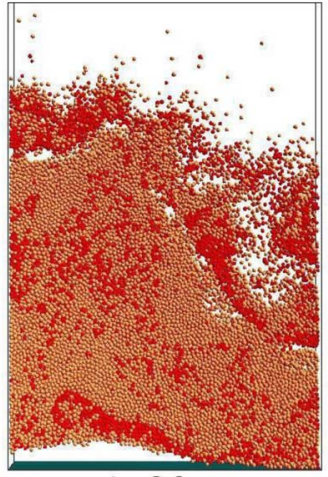

$t=0.3 s$

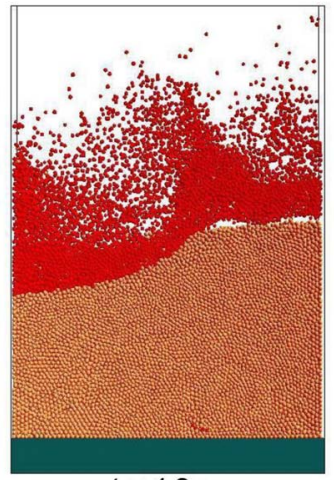

$\mathrm{t}=4.0 \mathrm{~s}$

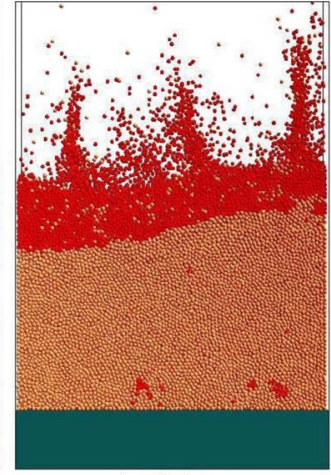

$t=1.3 s$

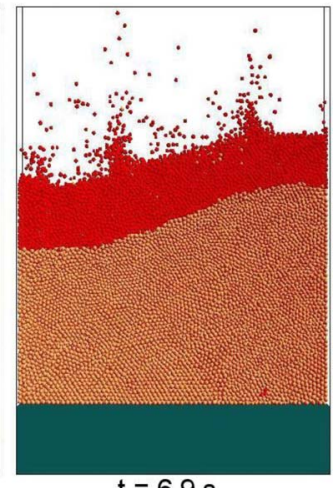

$t=6.9 s$
FIG. 7. (Color online) Series of snapshots leading to the bronze-on-top structure $\left(A_{z}\right.$ $=0.9 \mathrm{~mm}, f_{z}=55 \mathrm{~Hz}, \Gamma=11$ ) with low restitution coefficients. Bronze jets emerge from the bronze layer. These jets are formed by the increased energy dissipation in bronze-bronze collisions, caused by the low value of the normal restitution coefficient. system, where the purity of both phases is nearly perfect. Although tilting is observed, it is less frequent and no spilling of glass on top of the bronze layer is observed. Additionally, when bronze particles are launched from the top surface, bronze jets are formed, caused by the low normal restitution coefficient (see Fig. 7). When we do such a simulation for $f_{z}=130 \mathrm{~Hz}$ and $\Gamma=10$, we see the regular formation of the sandwich.

For both cases, we also investigated the effect of having a high value for the normal restitution coefficient, namely, 0.995. For these cases, we found similar results as for the 0.97 cases.

In conclusion, we find that the particle-particle and particle-wall collision parameters have a limited influence on the segregation phenomena, except for the friction coefficient for the sandwich system. In that case, the bronze layer may end up on top, in the middle, or even on the bottom, depending on the values of the parameters. The common values $\mu_{p p}=\mu_{p w}=0.1$ derived for glass-glass interactions seem to correspond best with the experimental observations.

\section{Effect of the box dimensions}

We have studied the effect of different box dimensions and granular bed height on the two major segregation forms, namely, the sandwich and the bronze-on-top formations. For the bronze-on-top section, we choose $f_{z}=55 \mathrm{~Hz}, A_{z}$ $=0.9 \mathrm{~mm}(\Gamma=11)$ and for the sandwich section $f_{z}=130 \mathrm{~Hz}$, $A_{z}=0.147 \mathrm{~mm}(\Gamma=10)$. We used two different widths for the box $(8.25$ and $16.5 \mathrm{~mm})$ and, for each of these, three granular bed heights were tested $(3.2,6.5$, and $9.7 \mathrm{~mm})$. For the smallest width, we also tested a granular bed height of 19.5 $\mathrm{mm}$. We found that the observations were the same as for the reference system for all combinations of box width and granular bed height.

As mentioned earlier, we also performed simulations for a $3 \mathrm{D}$ geometry (ground area $4.4 \times 4.4 \mathrm{~mm}^{2}$, granular bed height $6.5 \mathrm{~mm}, 105600$ particles), where the gas phase is now evaluated in all three dimensions, and for these cases also we find both the sandwich as well as the bronze-on-top structure. In Fig. 8, the sandwich formation for the 3D case is shown.

The effect of the aspect ratio (width vs height of the granular bed) on the behavior of the sandwich formation is of particular interest, since an increased bed height would allow the formation of multiple sandwich layers (i.e., glassbronze-glass-bronze-glass, etc.). To this end, we have increased the granular bed height from 6.5 to $19.5 \mathrm{~mm}$, while keeping the width constant at the reference value of 8.25 $\mathrm{mm}$. We investigated two cases: (i) with and (ii) without wall friction on the principal cell faces. For both cases, we found a sandwich structure, although the final position of the bronze layer was different: the layer was located deeper below the granular bed surface for situation (ii). The fact that multiple sandwich layers do not occur can be explained by the basic mechanism discussed earlier. The sandwich layer follows from a top layer of bronze pounding on the glassrich layer below, which can happen only at the top of the bed, and not in the middle. So the formation of the sandwich is purely a surface effect and should be viewed as a bronzeon-top configuration, but with an additional glass layer on top. We expect to find this state for any bed height.

In conclusion, we found that the occurrence of the bronzeon-top and sandwich structures did not depend much on the 


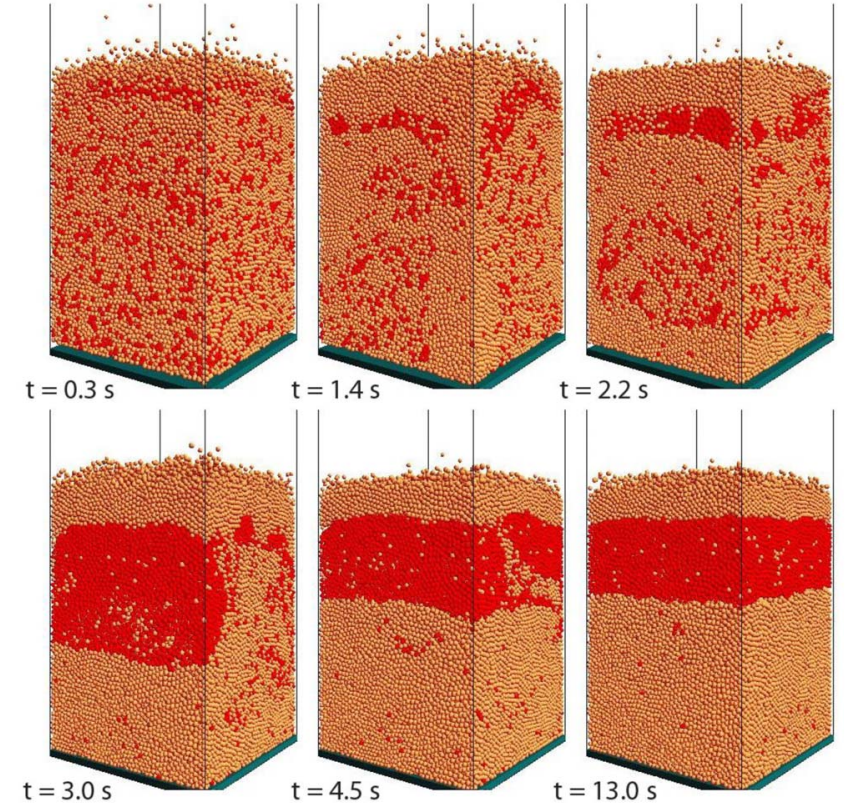

FIG. 8. (Color online) Series of snapshots from a 3D simulation, leading to a sandwich structure $\left(A_{z}=0.147 \mathrm{~mm}, f_{z}=130 \mathrm{~Hz}, \Gamma\right.$ $=10$ ).

box width or granular bed depth. It must be remarked, however, that the final position of the bronze layer in the sandwich structure depended on the friction coefficients, as illustrated earlier in Table II.

\section{Particle density ratio, initial conditions, and gravity}

We studied the effect of the density ratio $\rho_{\text {bronze }} / \rho_{\text {glass }}$ with simulations for the standard bronze-on-top case $\left(f_{z}\right.$ $=55 \mathrm{~Hz})$ and sandwich $\left(f_{z}=130 \mathrm{~Hz}\right)$ vibration parameters. Instead of using the density of glass $\left(2525 \mathrm{~kg} / \mathrm{m}^{3}\right)$, we used $1000 \mathrm{~kg} / \mathrm{m}^{3}$, thereby increasing the density ratio from 3.6 to 8.9. For bronze-on-top vibration conditions, we observed the regular tendency of the bronze moving to the top. However, the bronze does not easily remain on top, but exhibits tilting and forms a more sandwichlike structure. For $f_{z}=130 \mathrm{~Hz}$, we observe the regular formation of the sandwich structure, but the time required to do so is much smaller $(2 \mathrm{~s}$ compared to $10 \mathrm{~s}$ for the reference system). Apparently, for both the bronze-on-top and the sandwich system, the inertia in collisions of the bronze can explain these observations, since the reduction of mass means that the glass layer underneath is less able to withstand the pounding of the bronze clusters on top.

We investigated the effect of the initial situation of the granular bed (mixed or segregated) on the segregation. A simulation at bronze-on-top conditions with an initial sandwich structure still resulted in a bronze-on-top structure. However, a simulation at sandwich conditions with an initial bronze layer at the top did not lead to the sandwich formation.

We then determined the dependence of the observed segregation phenomena for bronze-on-top and sandwich condi- tions on the presence of the gravity force. To this end, we deactivate the gravity in a box with a height of $0.016 \mathrm{~m}$. The other simulation parameters are the same as in the reference situation. Since gravity is deactivated, the preferential direction of segregation can now be both upward and downward. Additionally, there is less mechanical energy input due to the smaller number of collisions with upper and lower system walls. For bronze-on-top conditions, we observe a number of bronze clusters meandering through the box. These clusters merge and break up continuously. The observed glass clusters are much larger. Like the bronze clusters, they are unstable and meander through the bed. Two porous sections with particles moving at high velocities (granular gas), are formed between the bottom and top.

\section{E. Mixtures with three components}

Up to now, in our reference system we have considered mixtures containing only two components, namely, 7500 bronze and 22500 glass particles. We now consider a threecomponent mixture, where, in addition to the bronze $\left(\rho_{s}\right.$ $\left.=8900 \mathrm{~kg} / \mathrm{m}^{3}\right)$ and glass $\left(\rho_{s}=2525 \mathrm{~kg} / \mathrm{m}^{3}\right)$, an additional component $X$ with a density of $6000 \mathrm{~kg} / \mathrm{m}^{3}$ is included. The composition of the mixture was chosen as 5000 bronze, 5000 $X$ and 20000 glass particles. We investigated three sets of vibration parameters, namely, (i) $f_{z}=55 \mathrm{~Hz}, \Gamma=11$ (bronze on top), (ii) $f_{z}=130 \mathrm{~Hz}, \Gamma=10$ (sandwich), and (iii) $f_{z}$ $=75 \mathrm{~Hz}, \Gamma=9$ (bronze on top), where the observation for reference conditions is placed in parentheses.

For case (i), we found that both bronze and $X$ went to the top and remained there in a mixed state. For case (ii), we found that initially bronze and $X$ sank as in the regular sandwich formation process, but the final position was only just below the bed surface and so one cannot speak of a true sandwich configuration.

Interestingly, for case (iii) we found that bronze and $X$ went to the top as in case (i), but after this, separation continued so that eventually a bronze- $X$-glass structure was obtained (see Fig. 9). In contrast with case (i), bronze and $X$ could separate and we suspect that this was caused by the less severe movement of the upper section of the granular bed.

We further investigated the absence of the sandwich in case (ii) by performing a simulation with a deeper granular bed $(9.5 \mathrm{~mm}$, compared to the reference value of $6.5 \mathrm{~mm})$. We changed the vibration parameters to $\left(f_{z}=125 \mathrm{~Hz}, \Gamma=9\right)$ and also increased the relative amount of glass. The mixture consisted of 7500 bronze, $7500 X$, and 30000 glass particles. We found that sinking of bronze and $X$ was initiated, but again the particles remained too close to the granular bed for the structure to be called a sandwich. We suspect that the sandwich formation was hindered by the dilution of the bronze with the lower-density component $X$.

\section{CONCLUSIONS}

We have found that most of the phenomena that have been observed experimentally for vertically shaken beds of glass and bronze particles are captured by our hybrid granu- 


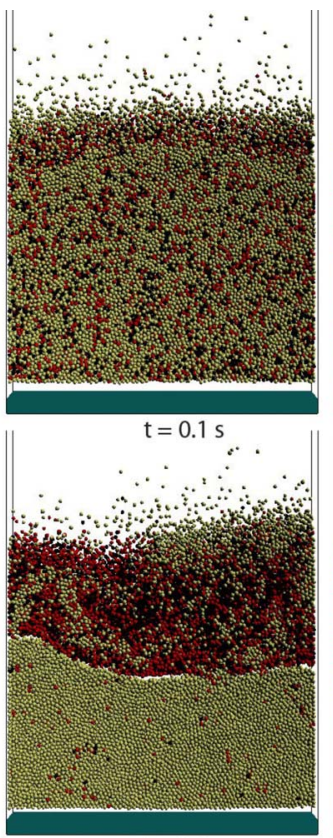

$\mathrm{t}=1.9 \mathrm{~s}$
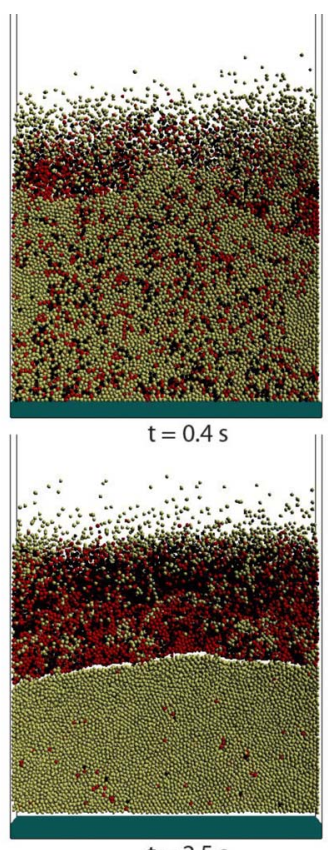
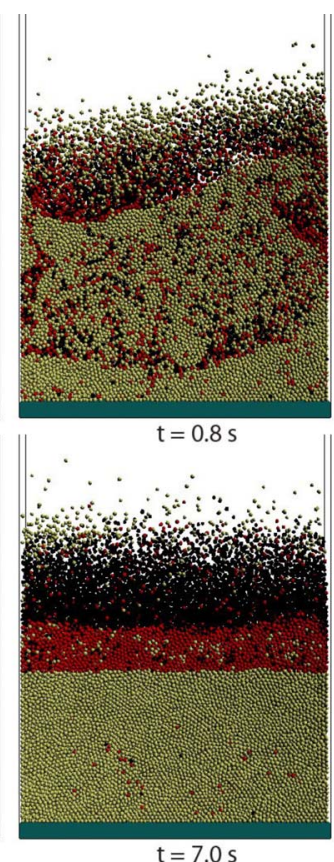

FIG. 9. (Color online) Series of snapshots leading to the bronze- $X$-glass structure $\left(A_{z}\right.$ $\left.=0.4 \mathrm{~mm}, f_{z}=75 \mathrm{~Hz}, \Gamma=9\right)$. Bronze and $X$ move up together to the top. After this, they slowly segregate into separate layers. lar dynamics-computational fluid dynamics model. Only the metastable regions, fluctuating between bronze-on-top and sandwich formations, are not observed. We suspect that this is caused by the limited size of the system $(8.25 \times 0.65$ $\times 6.5 \mathrm{~mm}^{3}$ ) that we studied, so that larger-scale instabilities may be supressed. We found that two distinct mechanisms are responsible for the different segregation forms. We further investigated the effects of pressure and air forcing, the effects of friction and restitution of kinetic energy in collisions, and the effects of box size on the segregation behavior. The formation of the bronze-on-top structure was found to be very robust and relatively independent of the gas and particle properties that we studied. The use of a mixture of particles with three different densities could even lead to a three-layer separation.

The formation of the sandwich structure, however, appears to be a rather subtle process, and the state is much less robust. We observed that it is rather sensitive to the particle properties; under the same shaking conditions, the bronze layer was found to end up in the middle (i.e., sandwich), on top or on the bottom, depending on the values for the friction coefficients. The state might not even be stable, as was already suggested from water-immersed experiments by Leaper et al. Clearly the formation and stability conditions of the sandwich structure require much further investigation.

\section{ACKNOWLEDGMENTS}

This work is part of the research program of the "Stichting voor Fundamenteel Onderzoek der Materie" (FOM), which is financially supported by the "Nederlandse Organisatie voor Wetenschappelijk Onderzoek" (NWO). It was further sponsored by the National Computing Facilities Foundation $(\mathrm{NCF})$ for the use of supercomputer facilities.
[1] H. M. Jaeger, S. R. Nagel, and R. P. Behringer, Rev. Mod. Phys. 68, 1259 (1996).

[2] E. Marring, A. C. Hoffmann, and L. P. B. M. Janssen, Powder Technol. 79, 1 (1994).

[3] S. J. Moon, I. G. Kevrekidis, and S. Sundaresan, Ind. Eng. Chem. Res. 45, 6966 (2006).

[4] M. Faraday, Philos. Trans. R. Soc. London 121, 299 (1831).

[5] H. K. Pak, E. Van Doorn, and R. P. Behringer, Phys. Rev. Lett. 74, 4643 (1995).

[6] B. Thomas and A. M. Squires, Phys. Rev. Lett. 81, 574 (1998)

[7] M. E. Möbius, B. E. Lauderdale, S. R. Nagel, and H. M. Jaeger, Nature (London) 414, 270 (2001).

[8] M. E. Möbius, X. Cheng, G. S. Karczmar, S. R. Nagel, and H.
M. Jaeger, Phys. Rev. Lett. 93, 198001 (2004).

[9] M. E. Möbius, X. Cheng, P. Eshuis, G. S. Karczmar, S. R. Nagel, and H. M. Jaeger, Phys. Rev. E 72, 011304 (2005).

[10] N. Burtally, P. J. King, and M. R. Swift, Science 295, 1877 (2002).

[11] N. Burtally, P. J. King, M. R. Swift, and M. Leaper, Granular Matter 5, 57 (2003).

[12] P. Biswas, P. Sánchez, M.R. Swift, and P.J. King, Phys. Rev. E 68, 050301(R) (2003).

[13] C. Zeilstra, M.A. van der Hoef, and J.A.M. Kuipers, Phys. Rev. E 74, 010302(R) (2006).

[14] M. A. van der Hoef, M. Ye, M. van Sint Annaland, A. T. Andrews IV, S. Sundaresan, and J. A. M. Kuipers, Adv. Chem. Eng. 31, 65 (2006). 
[15] P. A. Cundall and O. D. L. Strack, Geotechnique 29, 47 (1979).

[16] R. B. Bird, W. E. Stewart, and E. N. Lightfood, Transport Phenomena (Wiley, New York, 1960).

[17] D. Gidaspow, Multiphase Flow and Fluidization (Academic Press, Boston, 1994).

[18] Y. Tatemoto, Y. Mawatari, and K. Noda, Chem. Eng. Sci. 60, 5010 (2005).

[19] M. J. V. Goldschmidt, J. A. M. Kuipers, and W. P. M. van Swaaij, Chem. Eng. Sci. 56, 571 (2001).

[20] R. J. Milburn, M. R. Swift, and P. J. King, in Powders and Grains, edited by R. Garcia-Rojo, H. Hermann, and S. Mc-
Namara (Taylor \& Francis, London, 2005), p. 1029.

[21] M. A. Naylor, M. R. Swift, and P. J. King, Phys. Rev. E 68, 012301 (2003).

[22] M. C. Leaper, A. J. Smith, M. R. Swift, P. J. King, H. E. Webster, N. J. Miles, and S. W. Kingman, Granular Matter 7, 57 (2005).

[23] I. Goldhirsch and G. Zanetti, Phys. Rev. Lett. 70, 1619 (1993).

[24] J. Li and J. A. M. Kuipers, China Particuol. 2, 1 (2004).

[25] D. van der Meer, K. van der Weele, and D. Lohse, Phys. Rev. Lett. 88, 174302 (2002).

[26] A. H. Kharaz, D. A. Gorham, and A. D. Salman, Meas. Sci. Technol. 10, 31 (1999). 